This is a pre-print of a book chapter published in Gustavsson M, White C, Phillipson J and Ounanian $K$ (Eds.) Researching People and the Sea: methodologies and traditions. Palgrave Macmillan:

London. The final authenticated version is available online at [DOI will be available on publication in December 2020].

\title{
Reflections on methodological tensions in doing qualitative research at the science-policy- community interface
}

Ruth Brennan

\section{ruth.brennan@tcd.ie}

Trinity Centre for Environmental Humanities, School of Histories and Humanities, Trinity College, Dublin 2, Ireland

\begin{abstract}
Carrying out qualitative, participatory research at the science-policy-community interface can yield methodological tensions and present challenges for researchers. Sitting within the broader context of a long-running debate around the desirability of scholars' engagement with the policy environment, the chapter conceptualises three tensions that emerge at the science-policy-community interface, between: process and outcome; engaged research and advocacy; and applied policy research and critical theoretical research. It calls for greater attention to the energy, skills and time it takes to forge the relationships needed to do impactful research and for wider institutional support for policy-engaged academics.
\end{abstract}

\section{Introduction}

For over a decade now, I have been doing qualitative participatory research at the science-policycommunity interface on people and the sea. In this chapter, I contextualise my experience as an engaged researcher within the debates in the literature around whether we should, as critical scholars, be more hands-on with our policy engagement efforts, or whether this endangers the critical edge of our scholarship (and, indeed, our credibility as scholars). 
My reflections on methodological tensions in this chapter are contextualised in my current research project CO-SUSTAIN ${ }^{1}$, which focuses on co-designing approaches to small scale fisheries governance in island fishing communities off the west coast of Ireland. CO-SUSTAIN was designed as a participatory research project. The research is based on approximately twenty offshore islands in four island groups (Donegal, Mayo, Galway and Cork). The project design was informed by a communitybased organisation called the Irish Islands Marine Resource Organisation (IIMRO), which was set up in 2014 to amplify, and advocate for, the voices of small scale fishing communities on the Irish islands. IIMRO's roots lie in its predecessor, the Donegal Islands Marine Resource Organisation, which began engaging with the policy environment at national and European levels in 2006.

Since the start of my research career in 2007, I found myself gravitating towards methods that felt appropriate to the grounded and participatory nature of the research I was carrying out - hence my identification as a qualitative, participatory researcher. Years later, and largely thanks to conversations with feminist geographer and political ecologist Professor Andrea Nightingale, I discovered that these methods aligned with feminist approaches, with their attention to reflexivity, positionality, multiple ontologies and situated knowledge (see, for example, Blaser and de la Cadena 2018; Byrne and Lentin 2000; England 1994; Fonow and Cook 2005; Haraway 1988; Nightingale 2003; Sultana 2007). These approaches carry inherent tensions that pose particular dilemmas for doing qualitative research on people and the sea at the science-policy-community interface.

Though it is rarely acknoweledged, on a practical level, the engaged researcher expends much time and energy (emotional and intellectual) on finding ways to gain access to the policy process. A significant amount of perseverance and adaptability is needed, for example, to build relationships and networks,

\footnotetext{
${ }^{1}$ CO-SUSTAIN - Collaborative Sustainable Innovation: co-designing small-scale fisheries governance approaches in the Irish Islands. www.belongingtothesea.com
} 
trust, credentials, and in-depth policy-relevant knowledge (Cairney and Oliver 2017; Weible et al. 2012). Crucially, this effort involves careful positioning of expertise in such a way that it is invited into, or able to access, forums for potentially informing policy, whether it be advisory groups or key sciencepolicy meetings, or devising alternative routes to engage.

Networking, for example, proved crucial to achieving the aim of the CO-SUSTAIN research project. Gaining access to fishing-related fora, attended by policy and fisheries representatives, provided an opportunity for essential relationship building, which allowed the research project to be introduced informally. Face-to-face contact with potential interviewees, on the other hand, increased the chances of gaining access later to formal interviews. In turn, engagement in these kinds of settings increased the potential likelihood of the research to bring about change, by amplifying the voices of fishing communities through connecting the material realities of small-scale fishing with the prevailing policy context.

My personal experiences, together with the challenges identified in the literature, provide the background to the reflections in this chapter on tensions in the qualitative participatory research process at the science-policy-community interface. In the following sections, I situate these reflections within three categories of methodological tension, between: (i) process and outcome; (ii) engaged research and advocacy; and (iii) applied policy research and critical theoretical research.

\section{Tension between Process and Outcome}

In practice, qualitative participatory researchers who are active at the science-policy interface will often find themselves working with the tension between process and outcome. In my own experience, my focus tends to be on the research process, and seeing what emerges from this process, rather than working towards predefined outcomes. However, the first question from participants, policy makers and other academics, is often about what the desired research outcomes will be. This tension can 
manifest through the need to present research goals and outcomes in a summarised or policy-friendly way to increase the chances of accessing the policy environment. It means communicating in a language that is familiar to decision-makers and policy implementers, and focussing less on the language of the complex and non-linear reality of the qualitative research process (Donnelly et al. 2013; Lambotte and Meunier 2013).

It is difficult to generalise about this tension given the complexity and non-uniformity of participatory research approaches. In their review of participatory studies, Jagosh et al. (2011) limited their assessment of study outcomes to community-based participatory research. They sought to uncover the factors in the participatory research process that contributed to process or end results, using a contextmechanism-outcome framework. They highlighted that the context-mechanism-outcome (CMO) categories cannot be neatly separated when this framework meets the messiness and heterogeneity of participatory research. For example, they observed that where the CMO framework is applied to certain aspects of a research study (rather than to the study as a whole), one CMO might be embedded in another $\mathrm{CMO}$, or the outcome of one CMO might be the context for another.

In a similar vein, even when the non-linear nature and practical 'messiness' of engaged/participatory/qualitative research process is recognised, it is difficult for this to be captured in methodology classes and textbooks. This creates a tension between what we may have been taught or read, and what we experience in practice on the ground in doing research, particularly when the research interfaces with the realm of policy.

Difficulties also arise when trying to measure the impact of participatory research outcomes. Bowman et al.'s (2018) framework and metrics for measuring the impact of qualitative 'engaged research' supports a project strategy divided into 'impacts : activities : outputs : anticipated outcomes : desired (longer term) impacts'. Despite its usefulness in identifying metrics that convey the impacts of engaged 
research, the framework does not necessarily sit easily with the often unfolding and open-ended, participatory research approach in practice.

\section{Tension between Engaged Research and Advocacy}

At the outset of participatory research projects and indeed, even before this, at the research design stage, and at various points during the research, I am careful to explain my role as a researcher and look to distinguish it from that of an advocate. Asserting this position requires sensitivity and careful management of research relationships built up with participants. This is not always straightforward. The hands-on and applied approach, which is implicit to engaged research, can often be interpreted as advocacy.

As engaged researchers we wrestle with the notion of advocacy and by and large tend to try and distance ourselves from it. Roger Pielke (2007) identifies four idealised roles of science engagement in policy and politics: the 'Pure Scientist' (if they exist) focuses on research without considering its use or seeking a desired outcome; the 'Science Arbiter' answers empirical (as opposed to normative) questions for the decision-maker or policy implementer without seeking a desired outcome; the 'Issue Advocate' considers the implications of the research for a particular political agenda and seeks a desired outcome aligned with the interests of a group; and the 'Honest Broker of Policy Alternatives' provides insight into the choices available to decision-makers and policy implementers, by using scientific knowledge and stakeholder concerns to inform alternative ways forward. In relation to the Issue Advocate, Pielke (2007) distinguishes between Issue Advocacy (which he argues can be a valid and worthwhile role for scientists in public debates) and Stealth Issue Advocacy, where the expert either seeks to hide their advocacy behind a façade of science ostensibly untainted by politics, or the expert is genuinely unaware of the conflation of science and politics in their advice. Pielke's framework points to a need for reflexivity on the part of the engaged researcher, in order to consciously choose how they position 
themselves vis-à-vis their engagement in policy and politics, and to continue to question and (if necessary) adjust their positionality throughout the research process.

By doing applied research at the science-policy-community interface, researchers can contribute to shaping (hopefully better) policy. There is, of course, a normative element to this kind of engagement, as our values inform what we consider to be 'good' (see Mee et al. 2008). Taking the CO-SUSTAIN project as an example, my engagement is not just with island communities - I also actively engage with politicians and policy makers, for example by providing advice, briefings, policy statements and responses to policy consultations. Through this work it is not uncommon to be seen as an advocate for certain agendas that may align with the standpoints of organisations that are calling for change in policy processes. Indeed, one of the roles of the engaged scholar can be to challenge the status quo, particularly when there appear to be power imbalances at play. In this situation it can be difficult to carry out critical and independent participatory qualitative research, without it being seen as advocacy. This leads me to the third tension that can often be experienced; that between applied policy research and critical theoretical research.

\section{Tension between Applied Policy Research and Critical Theoretical Research}

The (feminist) political ecology literature has often discussed the dilemma as to whether engaging with policymakers is desirable and whether this engagement risks jeopardising and diluting the critical nature of research (see, for example, Batterbury 2015; Bebbington 2015; Blaikie 2012; Carr 2011; McCusker 2015; Nightingale 2018a; Walker 2006). In a review of the literature on engagement between political ecologists and policy makers, McCusker (2015) found that there is a notable and longstanding lack of attention paid by scholars to policy making and policy implementation. In 2006, Peter Walker's article 'Political Ecology: where is the policy?', similarly reflected on the reasons for the limited engagement of political ecologists with the policy environment and, in turn, the rejection by policy makers of 
political ecology scholarship. Walker $(2006,391)$ articulated several challenges for engagement, including:

'...doing a much better job of communicating to the outside world what the field has to offer, and how these ideas can be used appropriately, including the explicit exposition of alternatives as well as critiques. What are the most important 'seeds' political ecologists wish to plant? Where will they be planted? How will they be tended to assure they are not co-opted or distorted? Until the subfield can respond to these questions effectively, it can be expected that fields with more narrow perspectives that reinforce the status quo will dominate public debates and decision-making, leaving political ecology to the verdant but largely peripheral pastures of academia.'

The challenges identified by Walker reflect the tensions I have experienced in my own work: how to do this kind of engaged policy research, without being dismissed as not being critical enough by other academics; and how to bring concepts from critical theoretical research to the policy environment in an intelligible way, without being dismissed by policy makers as too critical or detached from the demands of the policy environment. For critical social scientists researching people and the sea, these dilemmas surface more and more as the management, planning and conservation of the marine environment is increasingly dominated by the language of Blue Growth and the reframing of the marine environment as the domain of the blue economy. This reordering of the marine space raises questions of equity of access and resource distribution (see Brent et al. 2018), yet there is seemingly little room for the contribution of the qualitative social scientist in addressing these questions.

If account is to be taken of the different ways of understanding 'nature' and human-nature relationships, broader questions of who has the power to bound, control and commodify nature are significant, as well as taking into account the relationship between the socio-natural environment and socio-political institutions. Finding space in policy engagement to broaden the policy framing is crucial. Take, for example, an alternative to the Blue Growth framework, the Blue Commons. This concept considers the 
ocean and marine resources as a common good, to be protected, restored and managed as a shared commons, that is accessible for small coastal communities as well as for industrial fishing fleets. This framing shifts the focus from industrial expansion and profit to collectivisation, social cohesion and belonging to nature. Bringing the concepts of the Blue Commons to a time-constrained policy table poses a challenge, not least because it begs consideration of the consequences, and the political nature, of choosing a particular frame and draws attention to a need to open up spaces to shape change.

An example of how this tension plays out in practice is one I witnessed at a marine policy symposium in a conversation initiated between geographer Dr Wesley Flannery (Queen's University Belfast) and Conor McCabe (head of the National Marine Planning Framework unit in the Department of Housing, Planning and Local Government). Both had delivered talks in the same session. Wesley Flannery had delivered a paper (Flannery et al. 2019) that was highly critical of opportunities missed by England in its marine spatial planning process. He set out an argument that characterised the post-political nature of marine spatial planning in England, in which the agendas of dominant actors have been cemented and the status quo maintained (Clarke and Flannery 2019). As the Irish National Marine Planning Framework team are in the process of bringing together and implementing a variety of existing sectoral policies as part of the marine planning process, this critique raised the potential red flag of pathdependent decision-making and plans being overly dominated by sectoral thinking. The conversations that ensued centered around the practical difficulties facing policy implementers in allowing room for manoeuvre in decision making and the academics' arguments that such room for manoeuvre needed to be explicitly written into the planning process in order to facilitate effective and equitable governance. The discussions provide a good illustration of Walker's $(2006,392)$ call for 'the explicit exposition of alternatives as well as critiques'. The academics in that symposium articulated strong counter-narratives grounded in critical scholarship and, combined with the vital and practical insights from those involved in policy delivery, they together sought to tease out how these could shape a more progressive marine spatial planning process. 


\section{Concluding Discussion: Working with the Tensions}

In this chapter, I have identified and contextualised three categories of methodological tension in doing qualitative research on people and the sea at the science-policy-community interface: tensions between (i) process and outcome; (ii) engaged research and advocacy; and (iii) applied policy research and critical theoretical research. I have discussed the challenges of navigating the non-linear realities of the qualitative, participatory research process while engaging with a policy environment that is constrained by specific timeframes and expectations regarding language and concrete outcomes. Engaging in this process as a researcher calls for constant reflexivity as to the researcher's positionality along the spectrum of engaged researcher to issue advocate. Time and skill is required from the critical scholar in positioning themselves to seed new concepts in the policy domain that may question the status quo - and also in being able to potentially navigate challenges to the scholar's own academic status, should they be considered to have devalued their research by engaging with the policy environment.

For the CO-SUSTAIN project I sought out a strong theoretical framework to help me to work with and navigate (not necessarily resolve) the tensions in my research approach. I chose to work with the socioenvironmental state framework developed by feminist geographer and political ecologist Professor Andrea Nightingale. Nightingale (2018b) argues that the actions and choices involved in governing resources shape what she calls the socio-environmental boundaries of the state. She contends that this is important because it influences how future transformations can unfold - for example opportunities for transformation in governance may be missed, or people, groups and institutions may be excluded, because of the ways in which these boundaries are being made and remade. She theorises three different boundary framings (state-society; society-nature; and citizenship-belonging) to capture the complex interplay between attempts to govern a dynamic world and the inadvertent authorisations, inclusions and exclusions produced by these attempts to govern. 
In the CO-SUSTAIN project, I used this framework to think about overlapping authorities between State institutions and the community organisation IIMRO, and what this means for island fisheries governance. For example, who benefits in circumstances when authority is unclear? Who has the power to leverage that lack of clarity and claim authority? I also used the framework to think about how narratives of islandness and marginalisation are being used by islanders to achieve recognition of authority at different scales - local, regional, national and European.

As the socio-environmental state framework is inherently about relationality and relationships, not just between humans but also between the human and more-than-human world, it embodies a focus on process that helped to navigate the tension between process and outcome. Moreover, its engagement with situated politics and processes grounds it in day-to-day realities, while the critical abstraction of the framework speaks to the critique of advocacy and insufficient critical thought as to policy framings.

Although theoretical frameworks offer one way to navigate the tensions and challenges faced by engaged researchers at the science-policy-community interface, it is clear that they must be accompanied by a significant investment of time and energy. More and more, academic institutions are being encouraged to champion policy-engaged research. What is perhaps missing from this debate is greater attention to the requisite capacity building and career support, that is needed to underpin a trajectory of engaged scholarship, to build up a cohort of skilled, engaged researchers that can operate at this interface (Andrews et al 2020; Evans and Cvitanovic 2018).

Building strong working relationships with those within the policy environment, not only takes time, energy and skilful manoeuvring, but is an inherently political act on the part of the academic and policy staff alike. They together have the potential to provide fertile ground for challenging conventional and dominant narratives and developing effective and compelling counter-narratives to contribute to a more equitable and sustainable society (Leach and Mearns 1996; Roe 1991; Walker 2006). 


\section{Acknowledgements}

The reflections in this chapter are based on a paper I delivered at one of the three sessions on 'Researching people and the sea: methodologies and traditions' at the MARE People and the Sea X conference (25-28 June 2019). I thank the Marine Institute (Travel and Networking grant agreement NT/19/14) and TCD Association and Trust for funding support to attend the 2019 MARE People and the Sea X conference. This project has received funding from the European Union's Horizon 2020 research and innovation programme under the Marie Skłodowska-Curie grant agreement No 789524. The time to write this chapter has been supported by this grant.

\section{References}

Andrews, Evan J., Sarah Harper, Tim Cashion, Juliano Palacios-Abrantes, Jessica Blythe, Jack Daly, Sondra Eger, et al. 2020. "Supporting Early Career Researchers: Insights from Interdisciplinary Marine Scientists." ICES Journal of Marine Science 77 (2): 476-85.

https://doi.org/10.1093/icesjms/fsz247.

Batterbury, Simon. 2015. "Doing Political Ecology Inside and Outside the Academy." In The International Handbook of Political Ecology, edited by Raymond L. Bryant, 27-43. Glos and Massachusetts: Edward Elgar Publishing Limited.

Bebbington, Anthony. 2015. “At the Boundaries of La Política. Political Ecology, Policy Networks and Moments of Government." In Routledge Handbook of Political Ecology, edited by Tom Perreault, Gavin Bridge and James McCarthy, 198-208. Oxon and New York: Routledge.

Blaikie, Piers. 2012. "Should Some Political Ecology be Useful? The Inaugural Lecture for the Cultural and Political Ecology Specialty Group, Annual Meeting of the Association of American Geographers, April 2010.” Geoforum 43: 231-239. 
Blaser, Mario, and Marisol de la Cadena. 2018. "Pluriverse: Proposals for a World of Many Worlds." In A World of Many Worlds, edited by Marisol de la Cadena and Mario Blaser, 1-22. Durham and London: Duke University Press.

Bowman, Sarah, Kate Morris, and Maura Adshead. 2018. "A Framework for Engaged Research. Society and Higher Education Addressing Grand Societal Challenges Together. A How To Guide.” Accessed March 25, 2020. http://www.campusengage.ie/wpcontent/uploads/2018/12/Framework for Engaged Research May 18 Web.pdf.

Brent, Zoe, Mads Barbesgaard, and Carsten Pedersen. 2018. The Blue Fix: Unmasking the Politics Behind the Promise of Blue Growth. Amsterdam: Transnational Institute. Accessed July 2, 2020.

https://www.tni.org/en/bluegrowth

Byrne, Anne, and Ronit Lentin, ed. 2000. “(Re)searching Women: Feminist Research Methodologies in the Social Sciences in Ireland.” Dublin: Institute of Public Administration.

Cairney, Paul, and Kathryn Oliver. 2017. "Evidence-Based Policymaking Is Not like Evidence-Based Medicine, so How Far Should You Go to Bridge the Divide between Evidence and Policy?" Health Research Policy and Systems 15 (1): 1-11. https://doi.org/10.1186/s12961-017-0192-x.

Carr, Edward, R. 2011. "If You Are Uncomfortable You Are Probably Doing It Right.” Environment and Planning A 43: 2792-2800.

Clarke, Jane, and Wesley Flannery. 2019. "The Post-Political Nature of Marine Spatial Planning and Modalities for Its Re-Politicisation.” Journal of Environmental Policy \& Planning, October, 1-14. https://doi.org/10.1080/1523908X.2019.1680276.

Donnelly, P.F., Yannnis, G. and Özkazanc-Pan, B. (2013). "Guest Editorial: Untold Stories of the Field and Beyond." Qualitative Research in Organizations and Management: An International Journal,. 8 (1): 4-15. 
England, Kim. 1994. “Getting Personal: Reflexivity, Positionality, and Feminist Research.”

Professional Geographer 46 (1): 80-89.

Evans, Megan C., and Christopher Cvitanovic. 2018. "An Introduction to Achieving Policy Impact for Early Career Researchers.” Palgrave Communications 4 (1). https://doi.org/10.1057/s41599018-0144-2.

Flannery, Wes, Ben McAteer and Jane Clarke. 2019. “Don’t Rule Britannia! An Evaluation of MSP in England." PowerPoint presentation, $10^{\text {th }}$ SEMRU Annual Marine Economics and Policy Research Symposium, Marine Institute, Galway, Ireland, November 28, 2019.

Fonow, Mary Margaret, and Judith A. Cook. 2005. "Feminist Methodology: New Applications in the Academy and Public Policy." Signs: Journal of Women in Culture and Society 30 (4): 2211-2236.

Haraway, Donna. 1988. Situated Knowledges. "The Science Question in Feminism and the Privilege of Partial Perspective.” Feminist Studies 14 (3): 575-599.

https://doi.org/10.1080/10714413.2012.643740.

IUA 2020. Irish Universities Association and Royal Irish Academy Webinar. Evidence Informed Policy Making - the Role of Higher Education and Research. Accessed July 2, 2020.

https://www.iua.ie/events/iua-ria-webinar-evidence-informed-policy-making-the-role-of-highereducation-and-research-tuesday-30-june-11-30-12-30/

Jagosh, Justin, Pierre Pluye, Ann C Macaulay, Jon Salsberg, Jim Henderson, Erin Sirett, Paula L Bush, et al. 2011. "Assessing the Outcomes of Participatory Research: Protocol for Identifying, Selecting, Appraising and Synthesizing the Literature for Realist Review." Implementation Science 6 (1): 24. https://doi.org/10.1186/1748-5908-6-24.

Lambotte, F. and Meunier, D. (2013). "From Bricolage to Thickness: Making the Most of Messiness of Narrative Research." Qualitative Research in Organizations and Management: An International 
Journal 8 (1): 85-100.

McCusker, Brent. 2015. "Political Ecology and Policy: A Case Study in Engagement. In Routledge Handbook of Political Ecology, edited by Tom Perreault, Gavin Bridge and James McCarthy, 188197. Oxon and New York: Routledge.

Mee, Laurence D., Rebecca L. Jefferson, Dan d.A. Laffoley, and Michael Elliott. 2008. "How Good Is Good? Human Values and Europe's Proposed Marine Strategy Directive." Marine Pollution Bulletin 56 (2): 187-204. https://doi.org/10.1016/j.marpolbul.2007.09.038.

Nightingale, Andrea J. 2018a. “Geography’s Contribution to the Sustainable Development Goals: Ambivalence and Performance.” Dialogues in Human Geography 8(2): 196-200.

Nightingale, Andrea J. 2018b. "The Socio-Environmental State: Political Authority, Subjects and Transformative Socionatural Change in an Uncertain World." Environment and Planning E: Nature and Space 1 (4): 688-711.

Nightingale, Andrea J. 2003. "A Feminist in the Forest: Situated Knowledges and Mixing Methods in Natural Resource Management." ACME: An International E-Journal for Critical Geographies 2 (1): $77-90$

Pielke, Roger A. 2007. The Honest Broker: Making Sense of Science in Policy and Politics. The Honest Broker: Making Sense of Science in Policy and Politics. Cambridge University Press. https://doi.org/10.1017/CBO9780511818110.

Sultana, Farhana. 2007. "Reflexivity, Positionality and Participatory Ethics: Negotiating Fieldwork Dilemmas in International Research.” ACME: An International Journal for Critical Geographies 6 (3): 374-85. https://www.acme-journal.org/index.php/acme/article/view/786.

UCL 2020. UCL to lead $£ 3.9 \mathrm{~m}$ national collaboration to drive academic policy engagement. Accessed July 2, 2020. https://www.ucl.ac.uk/news/2020/jul/ucl-lead-ps39m-national-collaboration- 


\section{drive-academic-policy-engagement}

Walker, Peter A. 2006. “Political Ecology: Where is the Policy?” Progress in Human Geography 30(3): 382-395.

Weible, Christopher M., Tanya Heikkila, Peter deLeon, and Paul A. Sabatier. 2012. "Understanding and Influencing the Policy Process." Policy Sciences 45 (1): 1-21. https://doi.org/10.1007/s11077-011-9143-5. 